\title{
Henkilökuntaa, opiskelijoita ja potilaita kannattaa kuulla potilasturvallisuuskulttuurista
}

Asiasanat: potilasturvallisuuskulttuuri, potilasturvallisuus, potilasturvallisuuskulttuurikyselyt

Turvallisuuskulttuuri on se tapa, jolla organisaatio hoitaa turvallisuuteen liittyviä asioita kuten johtamista, töiden organisointia ja tiedonkulkua (1). Turvallisuuskulttuuri tulisi nähdä osana organisaatiokulttuuria, ja se tulisi nivoa osaksi kaikkea organisaation toimintaa, johon voidaan vaikuttaa samoilla tekijöillä kuten toimintaan muutenkin esimerkiksi johtamisella ja osaamisen kehittämisellä (2). Valtioneuvosto on kiinnittänyt huomiota potilasturvallisuuskulttuuriin. Sosiaalija terveysministeriön päivitetyn potilas- ja asiakasturvallisuusstrategian tarkoituksena on auttaa terveydenhuollon organisaatioita kehittämään ja toteuttamaan yhtenäistä turvallisuuskulttuuria. (3.)

Potilasturvallisuuskulttuuri on organisaation yhteinen näkemys siitä, mikä on turvallista toimintaa ja miten siihen päästään (2). Hyvä potilasturvallisuuskulttuuri on turvallisen toiminnan edellytys ja sillä voidaan parantaa potilasturvallisuutta.

Loppuvuodesta 2021 julkaistussa Valtioneuvoston koordinoiman TEAS-hankkeen loppuraportissa esitetään kansallinen potilasturvallisuuden seurantamalli ja mittaamisen standardit (4). Hankkeen yhteydessä muodostettiin systemaattisen kirjallisuuskatsauksen avulla kokonaiskuvaa kansainvälisesti käytetyistä potilasturvallisuusindikaattoreista. Niistä potilasturvallisuuskulttuuriin liittyvät julkaisut raportoitiin ja arvioitiin pro gradu -tutkimuksessa (5). Tutkimuksessa saatiin vastauksia siihen, miten ja millaisilla menetelmillä potilasturvallisuuskulttuuria on kuvattu ja arvioitu sekä millaisia yhteyksiä potilasturvallisuuskulttuurilla on tutkimuksissa osoitettu olevan potilasturvallisuuteen.
Tässä puheenvuorossa pohditaan, mitä hyötyä on potilaskyselyillä sekä henkilökunnalle ja opiskelijalle tehdyillä potilasturvallisuuskulttuurikyselyillä. Samalla tarkastellaan kyselyihin liittyviä haasteita.

\section{POTILASTURVALLISUUSKULTTUURI POTILASTURVALLISUUDEN EDELLYTYKSENÄ}

Potilasturvallisuuskulttuuri on käsitteenä vakiintumaton ja epäselvä ja se rinnastetaan usein lähikäsitteeseen turvallisuusilmastoon. Turvallisuusilmastolla tarkoitetaan pinnallista ja arviointihetkeen ja subjektiivisiin näkemyksiin perustavaa kulttuurin ilmentymää. Kulttuuri on kollektiivinen ominaisuus, joka perustuu syvempiin merkityksiin ja arvoihin. $(6,7$.)

Potilasturvallisuuskulttuurin katsotaan koostuvan eri osa-alueista - ulottuvuuksista - kuten johtamisesta, kommunikaatiosta, oppimisesta, virheisiin suhtautumisesta ja tiimityöskentelystä. Hyvä potilasturvallisuuskulttuuri luo edellytykset turvalliselle toiminnalle. $(2,8$.)

Hyvän potilasturvallisuuskulttuurin tunnistaa riittävistä resursseista ja siitä, että turvallisuus nähdään tärkeänä ja riittävän laajasti. Toiminnan vaaroista ollaan tietoisia ja turvallisuutta halutaan kehittää ja koetaan, että siihen voidaan vaikuttaa. Lisäksi sekä työntekijät että johto ymmärtävät turvallisuuden merkityksen. (2.) Positiiviselle turvallisuuskulttuurille on ominaista luottamuksellinen viestintä, yhteinen käsitys turvallisuuden tärkeydestä sekä luottamus ennaltaehkäisevien toimien tehokkuuteen (9).

\section{MITEN POTILASTURVALLISUUSKULTTUURIA ARVIOIDAAN?}

Kaiken terveydenhuollon toiminnan tulee olla vaikuttavaa, myös potilasturvallisuuteen liittyvien interventioiden. Terveydenhuollossa prosessien 
suoritteen ja vaikuttavuuden välinen yhteys ei välttämättä ole selkeä, koska lopputulokseen vaikuttaa esimerkiksi hoitomyöntyvyys tai diagnoosien tarkkuus. Siksi myös potilasturvallisuuteen liittyvien toimenpiteiden vaikuttavuuden arviointi on haastavaa. Ensisijaista on arvioida, johtuiko saatu vaikuttavuus juuri interventiosta. (10.)

Potilasturvallisuuskulttuurin mittaaminen ja eritoten sen vaikutusten mittaaminen on vaikeaa, koska sille ei ole vakiintunutta määritelmää ja se on ilmiönä moniulotteinen. Myös kulttuurin eri osatekijöiden toimivuutta on haasteellista mitata. Kulttuuria voidaan arvioida laadullisilla tapaustutkimuksilla esimerkiksi vakavien haittatapahtumien yhteydessä. Lisäksi kulttuuria voidaan arvioida vertailemalla eri organisaatioiden haittatapahtumien esiintyvyyttä. Tätä arviointia vaikeuttaa sekoittavat tekijät. Yleisin arviointitapa on säännöllisin väliajoin toteutetut kyselyt henkilöstölle. Niillä tutkitaan yleensä ilmapiiriä, joita pidetään kulttuurin indikaattorina. Kyselyt sisältävät kysymyksiä ja käsityksiä omista sekä työtovereiden ja esimiesten asenteista ja käyttäytymisestä. Tyypillisiä teemoja ovat muun muassa johdon sitoutuminen, työn kuormitus ja pätevyys. (11.) Potilaskyselyillä saadaan tietoa potilaan ja asiakkaan käsityksistä turvallisuudesta.

Potilas- ja asiakasturvallisuusstrategian tavoitteena on potilaan, asiakkaan ja omaisen roolin vahvistaminen potilasturvallisuuden edistämisessä. Potilaalle ja omaiselle tulisi antaa mahdollisuus osallistua hoidon turvallisuuden ja laadun varmistamiseen yhdessä hoitohenkilöstön kanssa. (3.) Potilaan käsityksiä potilasturvallisuudesta on tutkittu väitöskirjassa ja siinä on todettu, että potilaat raportoivat erilaisia vaaratilanteita yleisimmin tiedonkulkuun ja lääkitykseen liittyen ja että heillä on käytännöllisiä ja systeemilähtöisiä ratkaisuehdotuksia vaaratilanteiden toistumisen estämiseen (12).

Yleisimmät pro gradun tutkimusaineiston kyselyissä ilmenneet ulottuvuudet olivat organisaatioon liittyvät ulottuvuudet kuten johtaminen, resurssit, kommunikaatio, tiimityö ja oppiminen. Kyselyissä ilmeni myös psykologisia sekä sosiaalisiin prosesseihin liittyviä turvallisuuskulttuuriulottuvuuksia kuten turvallisuusmotivaatio, vastuu sekä suhtautuminen virheisiin. (5.)

Suomessa on kehitetty ja testattu potilasturvallisuuskulttuurin arviointi- ja kehittämismenetelmä (TUKU), jossa potilasturvallisuuskulttuu- rin osatekijät on eritelty psykologisiin tekijöihin, organisatorisiin tekijöihin sekä sosiaalisiin prosesseihin. Kyselyn lähtökohtana on, että turvallisuuskulttuuria voidaan kehittää osana terveydenhuollon organisaatioiden kokonaistoiminnan kehittämistä. (13.) Kyselyn validiteettitutkimuksessa todettiin, että organisaation turvallisuuskulttuuriulottuvuudet tunnistamalla ja niitä kehittämällä voidaan vaikuttaa potilasturvallisuuteen. Näitä ulottuvuuksia ovat avoin haittatapahtumien käsittely, syyllistämätön kulttuuri, yleinen työtyytyväisyys, tunne työn tärkeydestä sekä turvallisuusmotivaatio. Kyselyn todettiin sopivan hyvin muun muassa kulttuurin muutosten seuraamiseen. (14.) Toinen Suomessa yleisesti käytössä oleva turvallisuuskulttuurimittari on alun perin Agency for Healthcare Research and Quality -järjestön kehittämä HSOPSC-mittari (Hospital Survey on Patient Safety Culture), joka on muokattu ja testattu suomalaisessa ympäristössä (15).

\section{POTILASTURVALLISUUSKULTTUURIN ARVIOINNIN HAASTEET}

Turvallisuudessa on kyse käyttäytymisestä, kun taas kulttuurissa on kyse käyttäytymisen merkityksen ymmärtämistä (16). Siksi turvallisuuskulttuurin kehittämisessä tarvitaan tietoa siitä, miksi organisaatiossa toimitaan ja käyttäydytään tietyllä tavalla. Kulttuurin arvioimiseen ja kehittämiseen tarvitaan työntekijöiden ja potilaan näkemyksen lisäksi turvallisuuskulttuuriin vaikuttavien syvällisten tekijöiden tutkimusta. Niitä voidaan selvittää laadullisilla tutkimusmenetelmillä kuten haastatteluilla ja havainnoinnilla. $(1,17$.

Potilasturvallisuuden mittariksi turvallisuuskulttuurikyselyjen vastaukset eivät sinällään sovellu, koska tulokset kertovat henkilöstön käsityksen turvallisuuskulttuurista ja sen eri ulottuvuuksista, mutta eivät välttämättä sitä, mikä on todellinen tilanne. Kyselyjen vastauksia analysoimalla voidaan kuitenkin kehittää toimintaa turvallisempaan suuntaan.

\section{POTILASTURVALLISUUSKYSELYJÄ KANNATTAA TEHDÄ}

Vaikka turvallisuuskulttuuriin vaikuttavan käyttäytymisen tutkimus vaatii laadullista tutkimusotetta, on turvallisuuskulttuuria syytä pyrkiä arvioimaan myös kyselyillä. Pro gradu -tutkielman (5) perusteella kyselyjä voidaan pitää hyödyllisinä. Ne kertovat henkilöstön tai potilaan käsi- 
tyksistä turvallisuuskulttuurista ja antavat tietoa niistä turvallisuuskulttuuriin osa-alueista, joita tulisi kehittää. Näin henkilöstölle ja potilaalle tehdyt turvallisuuskulttuurikyselyt toimisivat kehittämistarpeiden kohteiden osoittajina. Kehittämistä vaativia osa-alueita voidaan tämän jälkeen tutkia tarkemmin esimerkiksi havainnoimalla tai haastattelemalla ja kehittää niiden perusteella toimintaa.

Kulttuurin muuttumisen ja muuttamisen on sanottu tapahtuvan hitaasti, koska kulttuuri on sidoksissa arvoihin sekä ihmisen totuttuihin käsityksiin ja toimintatapoihin, joiden muuttaminen tai muuttuminen on hidasta. Siksi kulttuurin muutokseen tarvitaan määrätietoista johtamista, aikaa ja vaivaa. (18.) Turvallisuutta tukeva toimintatapa olisi hyvä omaksua heti työuran alkuvaiheessa. Opiskelijalle tai heti ammattiuran alkuvaiheessa olevalle tehty kysely tukee turvallisuusajattelun omaksumista, jolloin turvallisuutta tukevasta toimintatavasta voi tulla pysyvää. Opiskelijoille tehtyjen kyselyjen tuloksia voitai- siin käyttää myös terveydenhuollon ammattihenkilöiden koulutuksen suunnitteluun, jotta koulutus tukisi työelämässä vastavalmistuneiden turvallisuuteen tähtäävää toimintatapaa.

Sen lisäksi että kyselyt ovat halpoja ja helppoja toteuttaa, voidaan niitä työelämässä käyttää osaamistarpeiden tunnistamisessa ja uusien työntekijöiden perehdytyssuunnittelussa. Pelkkien kyselyjen toteuttamisen on todettu parantavan turvallisuuskulttuuria (17) ja toimivan interventioina.

Pro gradu -tutkimus osoitti, että myös potilaat tunnistavat turvallisuuteensa liittyviä tekijöitä (5). Potilaan tai asiakkaan rooli turvallisuuskulttuurin paranemisessa on tunnistettu entistä tärkeämmäksi osaksi turvallisuuskulttuurin kehittämistä. Potilas- ja asiakasturvallisuusstrategiassa korostetaan potilaan tai asiakkaan roolia turvallisen ja laadukkaan hoidon varmistamisessa muun muassa kannustamalla tuomaan esille turvallisuudessa tai laadussa havaitsemiansa puutteita tai kehittämistarpeita. (3.)

Potilasturvallisuuskulttuurikyselyt:

- osoittavat toiminnan kehittämiskohteita,

- antavat tietoa perehdytyksen suunnitteluun, osaamistarpeiden tunnistamiseen ja täydennyskoulutuksen suunnitteluun,

- ovat helppoja ja halpoja toteuttaa ja

- toimivat interventioina lisäämällä tietoisuutta turvallisuuskulttuurista.

Päıvi Ylitalo

Korvausasiantuntija, YTM, kätilö, th Potilasvakuutuskeskus

\author{
Kaisa HaAtainen \\ Potilasturvallisuuspäällikkö, FT, dosentti \\ Sosiaali- ja terveydenhuollon EMBA \\ Kuopion yliopistollinen sairaala, \\ Sairaanhoidon hallinto \\ Itä-Suomen yliopisto, Hoitotieteen laitos
}

\section{LÄHTEET}

(1) Reiman T, Pietikäinen E, Oedewald P. Potilasturvallisuuskulttuuria kehittämällä huomio turvallisen työnteon edellytyksiin. Kirjassa: Kinnunen M, Peltomaa K. (toim.) Potilasturvallisuus ensin. Helsinki: Hoitotyön vuosikirja, Suomen sairaanhoitajaliitto ry; 2009, 63-76.

(2) Reiman T, Pietikäinen E \& Oedewald P. Turvallisuuskulttuuri. Teoria ja arviointi. Espoo: VTT Publications 700; 2008, 20; 13-14; 89.
(3) Sosiaali- ja terveysministeriön julkaisuja 2020:1. Potilas- ja asiakasturvallisuusstrategia 2017-2021. Toimeenpanosuunnitelma. Luettu 8.2.2011. http://urn.fi/ URN:ISBN:978-952-00-4133-5

(4) Potilas- ja asiakasturvallisuuden kehittämiskeskus 2020. Potilas- ja asiakasturvallisuuden tilanne ja seuranta VN TEAS -hanke "Potilasja asiakasturvallisuuden tilannekuva ja seurantamenettelyt". 
https://www.vaasankeskussairaala.fi/potilas-ja-asiakasturvallisuuden-kehittamiskeskus/ asiantuntijoille/potilas--ja-asiakasturvallisuudentilannetta-ja-seurantaa-selvitetaan/

(5) Ylitalo, P. Kuopio: Itä-Suomen yliopisto

Pro Gradu; 2021. http://urn.fi/ urn:nbn:fi:uef-20210713

(6) Ostroff C, Kinicki A, Muhammad R. Organizational Culture and Climate. Handbook of Psychology; 2003;12:643-676. doi: 10.1002/9781118133880.hop212024

(7) Guldenmund F. The nature of safety culture: a review of theory and research. Safety Science 2000;34:215-257.

doi: 10.1016/S0925-7535(00)00014-X

(8) Halligan M, Zecevic A. Safety culture in healthcare: a review of concepts, dimensions, measures and progress. BMJ Qual Saf 2011;20:338-343.

doi: 10.1136/bmjqs.2010.040964

(9) Flin R. Measuring safety culture in healthcare: A case for accurate diagnosis. Safety Science 2007;45:653-667.

doi: 10.1016/j.ssci.2007.04.003

(10) Torkki P, Leskelä R-L, Linna M. ym. Ehdotus sosiaali- ja terveyspalveluiden uudeksi kansalliseksi mittaristoksi. Valtioneuvoston selvitys- ja tutkimustoiminnan julkaisusarja 36/2017:28-36. Luettu 23.4.2020. http://urn.fi/URN:ISBN:978-952-287-383-5

(11) Ruuhilehto K, Vilppola K. 2000. Turvallisuuskulttuuri ja turvallisuuden edistäminen yrityksessä. Tukes-julkaisuja 1/2000. Luettu 27.3.2020. https://docplayer.fi/2179026-
Turvallisuuskulttuuri-ja-turvallisuudenedistaminen-yri-tyksessa-kaarin-ruuhilehtokatja-vilppola-vtt-automaatio-riskienhallinta. html

(12) Sahlström M. Patient participation in promoting patient safety: Finnish patients and patient safety experts views. Kuopio: Itä-Suomen yliopisto. Väitöskirja No 4; 2018. http://urn.fi/URN:ISBN:978-952-61-2961-7

(13) Pietikäinen E, Reiman T, Oedewald P. Turvallisuuskulttuurityö organisaation toiminnan kehittämisenä terveydenhuollossa. Espoo: VTT tiedotteita 2456, 2008:6-8.

(14) Reiman T, Silla I, Pietikäinen E. The validity of the Nordic patient safety culture questionnaire (TUKU). Int J Risk Saf Med 2013;25:169-184. doi: 10.3233/JRS-130595

(15) Turunen E, Mäntynen R, Kvist T. ym. Sairaalan potilasturvallisuuskulttuuri sairaanhoitajien arvioimana: pitkittäistutkimus yhden yliopistosairaalan erityisvastuualueella. Hoitotiede 2015;27:148-162.

(16) Guldenmund F. (Mis)understanding Safety Culture and Its Relationship to Safety Management. Risk Analysis 2010;30:14661480. doi: 10.1111/j.1539-6924.2010.01452.x

(17) Sorra J, Dyer N. Multilevel psychometric properties of the AHRQ hospital survey on patient safety culture. BMC Health Serv Res 2010;10. doi: 10.1186/1472-6963-10-199

(18) Harisalo R. Organisaatioteoriat. Tampere: Tampere University Press; 2008:272-273. 